\title{
Research on Effective Learning Strategies among Schools under Internet Environment
}

\author{
Qingjiang Li and Yumei Guan
}

\begin{abstract}
In this paper, a novel teaching method is proposed, which is realized by employing the network technology based on intercollegiate cooperation. The proposed inter-school network collaborative learning is a special teaching method of remote cooperative learning. The particularity is embodied in being able to extract the excellent teaching resources from other school. Under the network environment for the intercollegiate cooperation, the interests of students can be greatly motivated. And the learning efficiency can also be obviously improved. The concrete concept of inter-school network collaborative learning is analyzed and its advantages are also presented in this paper. Finally, a investigate experiment is carried out based on different subjects and terms. The results show that the average score, the percentage of proficiency and pass are clearly enhanced by utilizing the inter-school network collaborative learning.
\end{abstract}

Index Terms-Network technology, intercollegiate cooperation, effective learning.

\section{INTRODUCTION}

Narrow gap between schools, promote the balanced development of education, it is a strategic task put forward the Education Department released the latest national medium and long-term educational reform and development plan in. Summary pointed out, the key to narrow the gap between schools; the weak school reform is to improve the teacher's level [1]. In this study, will be in the quality school and weak school established intercollegiate cooperation relations, the creation of student interscholastic collaborative learning and Teacher Collaborative Teaching and research activities, in order to improve the weak level of school teachers, shorten the distance between schools, so as to achieve the purpose of balanced development of education.

With respect to the ineffective and inefficient in terms of effective learning to learn, learning is that students in teachers organize teaching activities, participate actively and efficiently obtain knowledge, skills and ability to grow new subject learning activities [2]. Here, effective and efficient effective contains two tiers of meaning. Make the students based on existing knowledge experience and ability, in the

Manuscript received June 12, 2019; revised November 12, 2019. This work was supported in part by the Qiqihar Medical University, China. Paper titles should be written in uppercase and lowercase letters, not all uppercase. Avoid writing long formulas with subscripts in the title; short formulas that identify the elements are fine (e.g., "Nd-Fe-B"). Do not write "(Invited)" in the title. Full names of authors are preferred in the author field, but are not required. Put a space between authors' initials.

Q. J. Li is with the Qiqihar Medical University, China (e-mail: 94127792@qq.com).

Yumei Guan is with Heilongjiang Communications Polytechnic, Qiqihar 161002, China (corresponding author). collaborative learning activities in intercollegiate multivariate, find the difference, learning differences, mutual inspiration, and improve together [3].

This paper proposes three new kinds of intercollegiate learning based on network, which are the teaching implementation process of establishing intercollegiate cooperative alliance, developing multi-level intercollegiate distance cooperative learning, and integrating intercollegiate collaboration organically. Finally, based on the pass rate and excellent rate of the relevant courses of students, a statistical study was conducted, and it was found that there was a significant improvement.

\section{THE CONCEPT AND ADVANTAGES OF INTER-SCHOOL NETWORK COLLABORATIVE LEARNING}

\section{A. The Concept of Inter-school Network Collaborative Learning}

Before the introduction of collaborative learning development process and research results, it is necessary to define related concepts. Usually, remote cooperative learning is that: located between geographically isolated cases of learners, for common goals or tasks and developing cooperation work study [4]. There is also a 'distributed collaborative learning' concept similar to this concept, it usually refers to: located between distributed network environments in between learners, that is located in the geographic separation of most learners' negotiation of cooperative learning.

These two concepts in common is: separation mentioned geographical concept, is not merely refer to leave a certain distance, but also to study participants between could not face-to-face communication situation. Usually, collaboration and cooperation is the same meaning [5]. The main difference is that, the group objectives and team members are composed of different.

In addition, 'collaborative learning based on network' refers to the development of a common theme: inter school learning activities using the Internet, and pay attention to the differences between learning in schools, mutual use this difference to carry out learning, such as developing a common theme of investigation or works based on the, and other social practice activities, to enhance the students to deepen the understanding of knowledge [6]. Therefore, it is a special type of remote cooperative learning, in the learning objectives, learning form and remote cooperative learning is basically the same as usual? The difference is, compared with the loose starts in the students' interest, the individual, as a unit to participate in the activities of remote cooperative 
learning; it is in the school organization, as groups, organized learning activities, plan [7].

\section{B. Advantages of Network Collaborative Learning}

As mentioned above, the development network interscholastic collaboration based on (cooperation) learning can cultivate the ability of many traditional classrooms ignored; in addition, interscholastic cooperative learning has the following advantages, also as shown in Fig. 1.

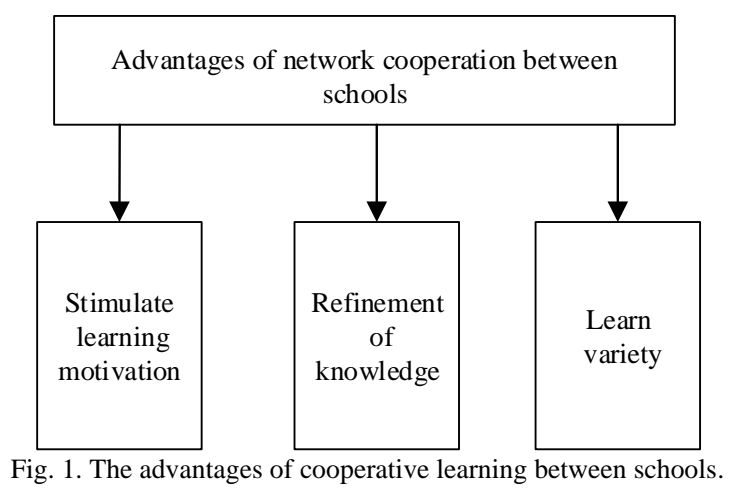

1) A large amount of information. On the same topic, dozens or even hundreds of schools to conduct a joint investigation, the amount of information they acquired, compared to a school for the unit to collect information disparity, and the students the teacher can experience sharing large amounts of data and information experience [8].

2) The common themes, regional differences, difference makes the survey results become obvious. Results the difference of diversity will induce students to further study.

3) The results of collaborative learning activities on the Internet gathering information increase the sense of reality. That, knows the other schools across the country partner in and of themselves, carrying out the same activities, students can experience the real value of the collected information.

\section{METHODS}

\section{A. Establish an Inter-school Cooperation Alliance}

Due to the great freedom of teaching in different universities and the differences in curriculum positioning and teachers' styles, different universities usually have different target positioning and content orientation. $\mathrm{C}$ language is a basic course for computer majors [9]. Through years of practice in many universities, $\mathrm{C}$ language has formed the unique teaching system and teaching advantages of each university.

The establishment of the inter-school cooperation alliance should not only strengthen the teaching links between schools, but also keep the teaching characteristics and advantages of each school. Full exchanges, draw on each other's strength, further strengthen discipline construction, and improve students' learning efficiency.

In this inter-university collaboration, Qiqihar university and Heilongjiang traffic vocational and technical college set up compulsory professional courses, while Qiqihar medical college set up optional professional courses. Qiqihar university attaches great importance to the construction of students' theoretical system, aiming at cultivating research-oriented talents; Heilongjiang traffic vocational and technical college attaches great importance to students' practical ability, and takes learning skills that meet social needs as the main goal; Qiqihar medical college aims at students' main application of $\mathrm{C}$ language.as shown in Fig. 2.

As is shown in the Fig. 2, in this inter-school alliance, each school will give play to its own advantages. Qiqihar University is mainly responsible for the output of theoretical knowledge of $\mathrm{C}$ language, while the other two universities focus on the output of practical teaching. The course $\mathrm{C}$ language is taught by combining theory with practice. Due to the participation of multiple roles such as collaborative teachers, network guidance, and inter-school students, an inter-school network learning community with diverse styles and mutual consultation and promotion has been formed.

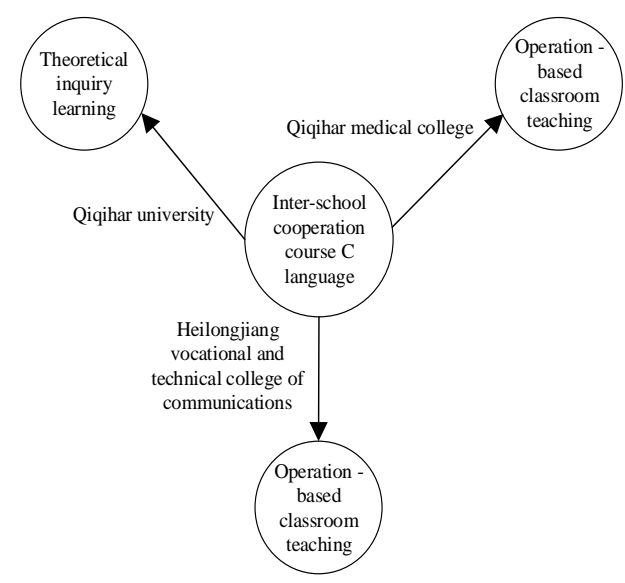

Fig. 2. Intercollegiate cooperation of the three universities has the advantage of teaching.

\section{B. Inter-school Distance Collaborative Learning Model}

Distance cooperative learning is "Shared labor" learning in a "remote" environment where participants can study together via E-mail, chat software (QQ, BBS, or many other online learning tools and environments).In recent years, many articles have pointed out that distance cooperative learning is particularly suitable for developing inter-school cooperative learning among various universities, which has the following characteristics :1.Diverse perspectives, interests, interpretations, and experiences.2. Compare, contrast, or link similar views of different geographies.3. Communicate with teachers in different schools in a real way. At the same time, when students enrich their knowledge, the teacher team also improves in comparison.4. Enhance students' global awareness and sense of cooperation [10]. In the inter-school distance collaborative learning, we should give full play to the advantages of the Internet and share, learn and utilize information to the maximum extent. Let different schools fully display their teaching advantages, and let students have a more comprehensive access to the cutting-edge academic theories related to $C$ language and the hot technologies needed by the society.

In the inter-school cooperation carried out in this paper, inter-school remote cooperation uploaded the excellent courses of excellent teachers of the cooperative schools 
through mooch platform, and formed the $\mathrm{C}$ language practice part study group through QQ group [11].Theoretical learning and practical programming are divided into several groups for remote discussion and evaluation within the group. In addition to communicating with students in class, students can also discuss with other students who have the same interest in other schools. Diversified inter-school cooperation. In section $\mathrm{C}$ of this section, we will give a more comprehensive introduction to the methods of this inter-school cooperation.

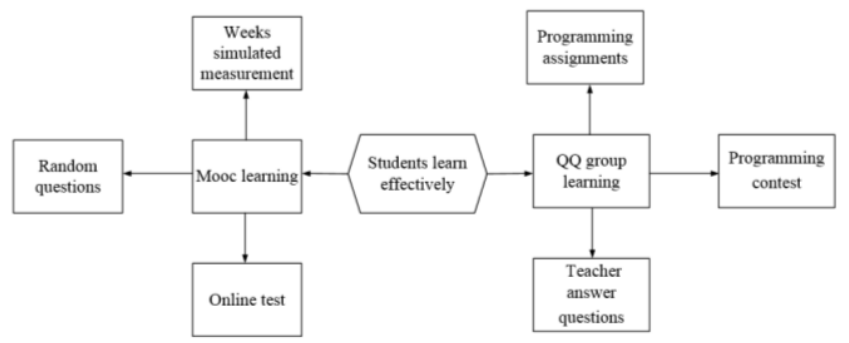

Fig. 3. The model chart of intercollegiate cooperative teaching based on Internet.

\section{The Teaching Implementation Process of Organic Integration with Inter-school Collaboration}

From the overall implementation of the curriculum, the combination of the advantages of the curriculum and the application of the Internet for teaching integration are part of the inter-school cooperation. In Fig. 3, we show how we use the Internet to carry out inter-school cooperation in $\mathrm{C}$ language teaching in the context of the Internet.

In the teaching process of $\mathrm{C}$ language, Take students' mastery as the main line, implement the online teaching mode of quality courses, random small problems in class, weekly simulation. QQ group is a programming contest. Interest exchange forms a mutual aid group, forming a good model of "boutique course learning -- network weekly test -- group programming contest -- mutual learning within the group -teacher q\&a" [12], [13].

As shown in Fig. 3, The three schools' collaborative learning modes are divided into online MOOC learning and QQ group learning, which are more conducive to the combination of theory and practice. In MOOC learning theory courses, teachers will use random questions in class and a weekly geodesy to enhance students' learning efficiency. In the practice of taking QQ group as the center, teachers release programming problems, students discuss them in groups, and conduct programming competitions with prizes on a regular basis to improve students' learning interest and efficiency.

Finally, we made a statistical analysis based on the results of MOOC and the questionnaire data of course efficiency for students, and described it in the IV (experimental results and data analysis) section.

\section{EXPERIMENTAL RESULTS AND ANALYSIS}

\section{A. Experimental Data Statistics and Analysis Methods}

This inter-university cooperation is mainly aimed at the $\mathrm{C}$ language courses offered by Qiqihar university (hereinafter referred to as A), Qiqihar medical college (hereinafter referred to as B), and Heilongjiang Jiao tong vocational and technical college (hereinafter referred to as $\mathrm{C}$ ). We believe that Qiqihar University has rich experience in the teaching of C language theory [14]. All quality MOOC courses are uploaded by teachers from the computer department of Qiqihar University. The teaching goal of Heilongjiang Jiao tong vocational and technical college is to train more talents in line with practice for the society, so the programming communication and grading through QQ group is completed by the teachers of the school. Qiqihar medical college, due to its teaching orientation, does not offer a major in computer science, so teachers are responsible for teaching models and data analysis in this inter-school cooperation [15].

\section{B. Data Result Analysis}

We have selected 125 students of computer science department of A university in 2017, and 131 students of computer science department of 2017.151 students majored in program design in 2017 in B university and 151 students majored in program design in 2018 in B university. There were 121 people in the radiology major of college $\mathrm{C}$ in 2017 and 132 people in the radiology major of college $\mathrm{C}$ in 2018 as data samples. Two types of indicators are selected. One is the pass rate and excellence rate of each school sample.

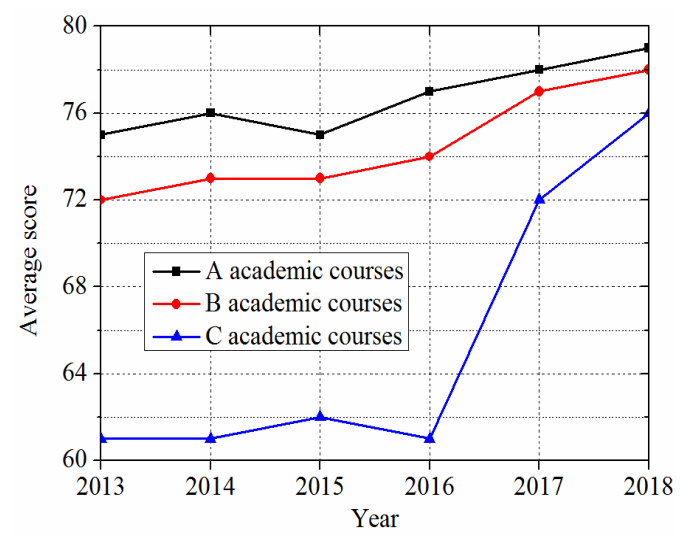

Fig. 4. 2013-2018 theoretical course scores of A, B and C universities.

Second, each school calculates the average score according to the MOOC high-quality course and QQ group practice proposed by us. In order to enhance the experimental effect, and we selected 6 years of data from 2013 to 2018. The experimental results are shown in Figs. 4 and 5.

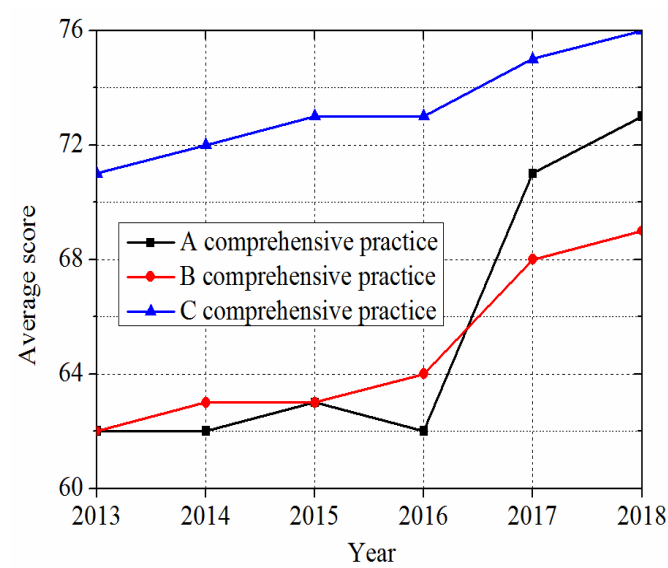

Fig. 5. Comprehensive practice achievements of A, B and C universities from 2013 to 2018 
As shown in Fig. 4 and Fig. 5, The change of student achievement after intercollegiate cooperation can be observed obviously. Due to A's strong theoretical knowledge, the academic evaluation performance of A has not changed significantly, but only improved to A small extent. We guess that it is because of the inter-school cooperation that students of A have increased their interest in learning and then improved their academic performance. However, due to the cooperation of $\mathrm{C}$ institutions, $\mathrm{C}$ has strong practical ability. As shown in Fig. 5, their comprehensive practice performance has been improved by about 10 points, and the effect is quite significant. University B has both excellent courses of university A and practical guidance of university C. Both MOOC scores and practical scores have been improved, but they are not as good as those of university A and university $\mathrm{C}$. The advantage of $\mathrm{C}$ University lies in practice. Practice scores have not changed much, but MOOCs have improved a lot.

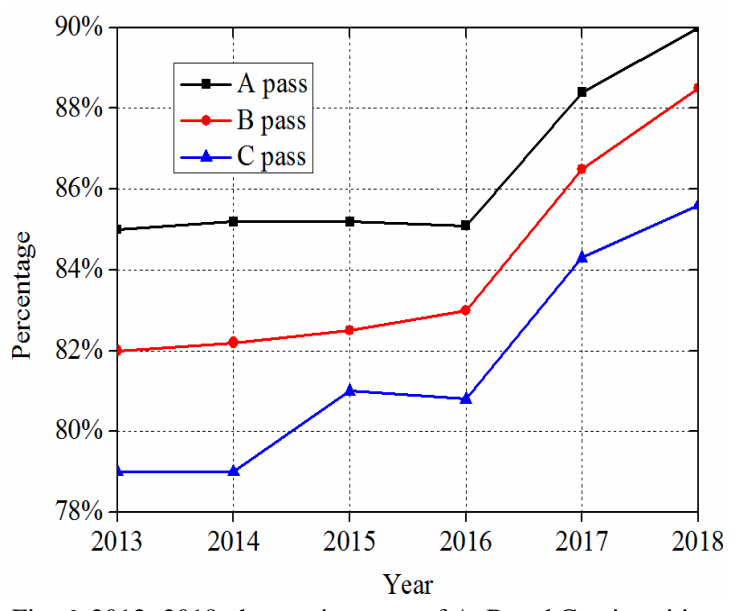

Fig. 6. $2013-2018$, the passing rates of A, B and C universities.

As shown in Fig. 6 and Fig. 7, both the passing rate and the excellent rate of the three institutions have been improved. Among them, the original excellent rate and the pass rate of A university are relatively high, so the increase of the passing rate and the excellent rate is relatively small.

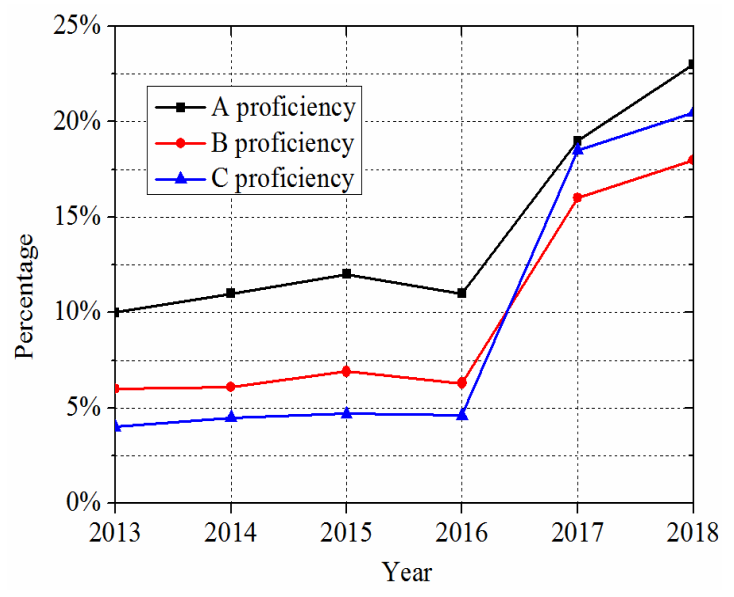

Fig. 7. 2013-2018, the university excellence rate of A, B and C universities.

$\mathrm{B}$ is in the middle, with an increase in pass rates, but not the most significant. The academic performance of college $\mathrm{C}$ has been greatly improved. It can be seen from Fig. 6 and Fig. 7 that the passing rate and excellent rate of college $\mathrm{C}$ have been improved most obviously. The passing rate has increased by about 8 percent, and the excellence rate by about 10 percent. Through the analysis of the four examination indexes of academic average score, comprehensive practice average score, pass rate and excellent rate, it is proved that intercollegiate cooperation can effectively improve students' learning efficiency and academic performance.

\section{CONCLUSION}

A new model of efficient learning based on inter-school network interconnection is presented in this paper. By investigating the basic concept of the inter-school network collaborative learning, three related methods of the research model are analyzed and given. Based on the three models, an experiment is constructed, which is utilized to prove the critical usefulness of the learning method. The results show that the average score, the percentage of proficiency and pass are clearly enhanced by utilizing the inter-school network collaborative learning.

\section{CONFLICT OF INTEREST}

The authors declare no conflict of interest.

\section{AUTHOR CONTRIBUTIONS}

In this paper, the preparation of the experiment and the collection of data are jointly completed by Qingjiang $\mathrm{Li}$ and Yumei Guan, in which Guan is responsible for the communication of teaching affairs between schools in the experiment .The analysis of experimental data and the compilation of the paper were finally completed by $\mathrm{Li}$.

\section{ACKNOWLEDGMENT}

This work was partially supported by the China Institute of Communications Education (CICE 1602-86).

\section{REFERENCES}

[1] H. Wu, M. J. Dai, and P. C. Wu, "Cooperation to differences in cooperation on the compulsory education in developed areas of urban development in the new thinking from the gap," China Education, vol. 5, 2008, pp. 10-12.

[2] X. W. Yang, "To explore the operation mechanism of the contemporary school change," Research and Experiment of Education, vol. 2, 2008, pp. 32-34.

[3] J. Huang and X. D. Xu, "Construction and practice of comprehensive thematic learning community," China Audio Visual Education, vol. 10, 2013, pp. 124-126.

[4] N. M. Golovin et al., "Evaluation of interaction between Russian universities and foreign universities," in Proc. the 2017 IEEE VI Forum Strategic Partnership of Universities and Enterprises of Hi-Tech Branches (Science Education Innovations) (SPUE), Nov. 2017.

[5] J. Tian and Z. Xia, "MOOCs in China's universities: Practice, characteristics and trends," in Proc. the 2017 3rd International Conference on Information Management (ICIM), April 2017.

[6] L. Tianfeng et al., "The effects of cooperative learning teaching mode in basketball lessons on the mental health of the college students," in Proc. 2011 International Conference on Human Health and Biomedical Engineering, Aug. 2011.

[7] L. Yang, "Reflection on cooperative learning in college English-reading teaching," in Proc. the 2011 IEEE International Symposium on IT in Medicine and Education, Dec. 2011.

[8] S. Yu and S. Li, "A cooperative authoring system for teaching chinese as a foreign language," in Proc. the 2006 10th International 
Conference on Computer Supported Cooperative Work in Design, May 2006.

[9] H. Zhao et al., "Study and exploration about quality assurance system of college graduation design based on cooperative teaching," in Proc. the 2017 IEEE 6th International Conference on Teaching, Assessment, and Learning for Engineering (TALE), 2017.

[10] P. Laforcade et al., "Profiling cooperative problem-based learning situations," in Proc. the Second IEEE International Conference on Cognitive Informatics, 2003.

[11] P. Laforcade et al., "Profiling cooperative problem-based learning situations," in Proc. the Second IEEE International Conference on Cognitive Informatics, 2003.

[12] J. C. PREY, COOPERATIVE learning in an undergraduate computer science curriculum," in Proc. the Proceedings Frontiers in Education 1995 25th Annual Conference Engineering Education for the 21st Century, 1995.

[13] M. Tan et al., "Statistical analysis on students' performance and their preference of course in bachelor of Engineering Technology programmers in Malaysian Spanish Institute, University Kuala Lumpur: Students performance versus programmer preferences," in Proc. the 2012 International Conference on Statistics in Science, Business and Engineering (ICSSBE), 2012.

[14] F. Chen, Z. Chen, and X. Jin, "Classroom education management and extension for colleges and universities," in Proc. the 2009 First
International Workshop on Education Technology and Computer Science, 2009.

[15] F. Chen et al., in Proc. the 2009 First International Workshop on Education Technology and Computer Science, 2009.

Copyright (C) 2020 by the authors. This is an open access article distributed under the Creative Commons Attribution License which permits unrestricted use, distribution, and reproduction in any medium, provided the original work is properly cited (CC BY 4.0).

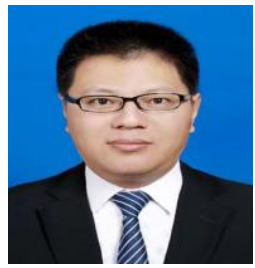

Qingjiang Li received the B.S. degree in computer science and technology from Qiqihar University, Qiqihar, Heilongjiang, China, in 2003, and the M.S. degree in software engineering from Heilongjiang University, Harbin, Heilongjiang, China, in 2009.

He was an assistant professor of Qiqihar Medical University from 2009 to 2013 , where he has been an associate professor since 2013. He was a visiting scholar in the college of computer and information science of Harbin Institute of Technology from 2018 to 2019. He has also been a member of Online Education of Computer Basic Education Research Association of Higher Education in China since 2018. His recent research interests include the medical image processing and the study of the basic computer education. 